\title{
Analisis Hidrokortison Asetat Dalam Sediaan Krim Pemutih Wajah Secara Kromatografi Cair Kinerja Tinggi
}

\author{
Herdini $^{* 1}$, Dwi Nurmalasari ${ }^{2}$, Veriah Hadi ${ }^{3}$ \\ ${ }^{1,2}$ Program Studi Farmasi, Fakultas Farmasi \\ ${ }^{3}$ Program Studi Fisika, Fakultas Sains dan Teknologi Informasi. \\ Institut Sains dan Teknologi Nasional \\ Jl. Moh. Kahfi II, Bhumi Srengseng Indah, Jagakarsa, Jakarta Selatan \\ *Email: herdinias69@istn.ac.id, nurmalasaridwi92@gmail.com, veriahadi@gmail.com
}

\begin{abstract}
Background Hydrocortisone acetate is an anti-inflammatory compound from the corticosteroid group. This active substance has a tendency to degrade during storage

Aim Given by that, it is necessary to determine the content of hydrocortisone acetate in facial whitening creams

Method In this study we determined by the reverse phase High Performance Liquid Chromatography (HPLC) method. The HPLC system used was column C18 $(4.6 \times 250 \mathrm{~mm})$, the mobile phase of the mixture of acetonitrile: aquabides (60:40), using a $252 \mathrm{~nm} U V$ detector. The results of the analysis showed good separation conditions with the mobile phase of acetonitrile, aquabides $(60: 40 \mathrm{v} / \mathrm{v})$ and a flow rate of $1.0 \mathrm{ml} / \mathrm{min}$. All components were separated in an analysis time of less than 2.0 minutes.

Result The results of the method validation show that the method used in this study meets the requirements of accuracy, precision, linearity, $L O D$ and $L O Q$. The results showed the method had good linearity $(r=0.9923)$. Accuracy results were $98.24 \%$ and $98.84 \%$. The precision result is $0.23 \%$. LOD results were $7.2601 \mu \mathrm{g} / \mathrm{mL}$ and LOQ results were $24.2004 \mu \mathrm{g} / \mathrm{mL}$.

Conclusion Based on the results obtained, all four cream samples containing hydrocortisone acetate with levels of each sample $A=1.0583 \mu \mathrm{g} / \mathrm{g}$, sample $B=0.3316 \mu \mathrm{g} / \mathrm{g}$, sample $C=$ $0.1513 \mu \mathrm{g} / \mathrm{g}$, and sample $\mathrm{D}=1.1662 \mu \mathrm{g} / \mathrm{g}$.
\end{abstract}

Keywords: Hydrocortisone acetate, Facial Whitening Cream, High Performance Liquid Chromatography

\section{PENDAHULUAN}

Kosmetika dikenal sebagai penunjang penampilan agar tampak lebih menarik. Seiring dengan berkembangnya ilmu pengetahuan dan teknologi beragam kosmetika muncul di pasaran. Menurut Peraturan Menteri Kesehatan Republik Indonesia No.1175/MENKES/PER/VIII/2010, kosmetika adalah bahan atau sediaan yang dimaksudkan untuk digunakan pada bagian luar tubuh manusia (epidermis, rambut, kuku, bibir, dan organ genital bagian luar) atau gigi dan membran mukosa mulut terutama untuk membersihkan, mewangikan, dan memperbaiki bau badan atau memelihara tubuh pada kondisi baik (Menteri Kesehatan Republik Indonesia, 2010a; Mohd Zukepli, Zakaria, \& Wan Omar, 2015).

Teknosains : Jurnal Sains, Teknologi dan Informatika is licensed under a Creative Commons Attribution-NonCommercial 4.0 International License.

Analisis Hidrokortison Asetat Dalam Sediaan Krim Pemutih Wajah Secara Kromatografi Cair Kinerja Tinggi (Vol.7, No1) Januari 2020 
Banyak pilihan produk kosmetika agar wanita terlihat lebih cantik salah satunya krim pemutih (whitening cream). Definisi dari krim pemutih adalah campuran bahan kimia atau bahan kimia lainnya. Krim pemutih dapat mencerahkan atau memutihkan noda-noda hitam dikulit. Suatu produk kosmetik sebelum dipasarkan harus dilakukan pengujian untuk menjamin mutu, keamanan dan kemanfaatanya dengan mencantumkan izin edar BPOM yang diatur dalam Peraturan Menteri Kesehatan Republik Indonesia No.1176/MENKES/PER/VIII/2010. Dalam beberapa kasus kandungan berbahaya dari kosmetik ilegal seperti merkuri, hidrokuinon, timbal dan lain-lain dapat menimbulkan berbagai efek seperti iritasi, jerawat, bahkan dapat menyebabkan kanker (Menteri Kesehatan Republik Indonesia, 2010b; Mohd Zukepli et al., 2015).

Hidrokortison merupakan senyawa turunan dari kortikosteroid yang berfungsi meredakan reaksi inflamasi seperti dermatitis, jerawat dan psoriasis (radang kulit akibat autoimun). Hidrokortison asetat merupakan obat yang penggunaanya perlu pengawasan dokter dan bahan ini sering disalahgunakan dalam formulasi krim pemutih yang tidak terdaftar izin BPOM. Penggunaan krim pemutih yang mengandung hidrokortison asetat dalam jangka waktu yang lama bisa menimbulkan berbagai efek samping seperti kulit menipis (atrofi), pembuluh darah permukaan kulit tampak lebih jelas (telangiektasia) dan lain-lain (Goldman \& Weiss, 2011; Ritter, Lewis, Mant, \& Ferro, 1981).

Penggunaan hidrokortison asetat tidak diperkenankan terdapat pada sediaan yang ditujukan untuk perawatan kulit, berdasarkan Peraturan Kepala Badan POM RI Nomor 18 Tahun 2015 tentang Persyaratan Teknis Bahan Kosmetik. Namun menurut laporan Badan POM RI seperti yang tertuang pada public warning No.IN.05.03.1.43.06.16.28.48 pada 2016 tentang kosmetik yang mengandung kortikosteroid. Hal ini tentu saja menunjukkan adanya pelanggaran terhadap peraturan yang ada dan menimbulkan kekhawatiran konsumen terhadap keamanan produk krim pemutih wajah yang digunakan (Badan POM RI, 2016; BADAN POM RI, 2015).

Kromatografi Cair Kinerja Tinggi (KCKT) merupakan metode analisis yang cepat, peka dan akurat dapat digunakan untuk analisis bahan organik dan anorganik, bersifat volatil dan non-volatil, stabil dan tidak stabil secara thermal, pilihan fase diam dan fase geraknya luas. Secara teknis metode ini memiliki keuntungan antara lain mampu memisahkan molekulmolekul dari suatu campuran, kecepatan analisis dan kepekaan yang tinggi, dapat dihindari terjadinya kerusakan bahan yang dianalisis, resolusi yang baik, dapat digunakan bermacammacam detektor, kolom dapat digunakan kembali, mudah melakukan recovery (Harmita, 2004).

Berdasarkan uraian di atas maka perlu dilakukan penelitian mengenai analisis hidrokortison asetat dalam sediaan krim pemutih wajah yang beredar di wilayah Bogor secara kromatografi cair kinerja tinggi. Bogor merupakan salah satu kabupaten yang berada di provinsi Jawa Barat. Di wilayah Bogor banyak toko kosmetik yang menjual kosmetik dengan harga murah salah satunya krim pemutih wajah. Krim pemutih wajah teregistrasi dan tidak teregistrasi dapat dijumpai dengan mudah. Tujuan dari penelitian ini adalah untuk mengetahui ada tidaknya

Teknosains : Jurnal Sains, Teknologi dan Informatika is licensed under a Creative Commons Attribution-NonCommercial 4.0 International License. 
kandungan hidrokortison asetat dan jumlah kadar hidrokortison asetat dalam sediaan krim pemutih wajah yang beredar di wilayah Bogor.

\section{METODE}

Bahan. Standar Hidrokortison Asetat, bahan krim pemutih wajah, aquabides pro HPLC (merck), Asetonitril pro HPLC (Fisher Scientific), Metanol pro analisis (merck), asam asetat glasial pro analisis (merck). Metode analisis adalah metode eksperimen dengan menggunakan Kromatografi Cair Kinerja Tinggi. Dengan menggunakan metode teknik pemisahan molekul berdasarkan perbedaan pola pergerakan antara fase gerak dan fase diam untuk memisahkan komponen hidrokinon asetat (berupa molekul) yang berada pada sediaan krim.

\section{HASIL DAN PEMBAHASAN}

\subsection{Hasil Perolehan Sampel}

Sampel yang dianalisis adalah krim pemutih wajah yang dikumpulkan dari beberapa toko kosmetik yang berada di wilayah Bogor. Sampel dikelompokan menjadi tiga yaitu krim pemutih wajah yang teregistrasi, registrasi palsu dan tidak teregistrasi. Kriteria krim pemutih wajah teregistrasi adalah krim pemutih wajah yang terdapat nomor registrasi dan penandaan lain yang disyaratkan oleh Badan Pengawas Obat dan Makanan dan penandaan tersebut tercantum dalam kemasan produk yang dapat dilihat pada Tabel 1. Sampel diperoleh dari beberapa toko kosmetik di wilayah Bogor, sehingga diambil 2 merk sampel krim pemutih wajah teregistrasi, 1 merek sampelkrim pemutih wajah registrasi palsu dan 1 merk sampel krim pemutih wajah tidak teregistrasi. Empat merk sampel yang diperoleh lalu didokumentasikan dan masing-masing kelompok ditandai dengan kode. A dan B merupakan kode krim pemutih yang teregistrasi, C merupakan kode krim pemutih teregistrasi palsu sedangkan D adalah kode krim pemutih yang tidak tergistrasi.

Tabel 1. Penandaan pada kemasan krim pemutih wajah

\begin{tabular}{lcccc}
\hline \multicolumn{1}{c}{ Keterangan } & A & B & C & D \\
\hline Nama Produk & + & + & + & + \\
Nama dan Alamat Produsen & + & + & - & - \\
Ukuran Bersih $(\mathrm{g})$ & + & + & - & + \\
Komposisi & + & + & - & + \\
Penandaan dalam Bahasa Indonesia & + & + & - & + \\
No. Bets & + & + & - & - \\
No. Registrasi & + & + & + & - \\
Tanggal kadaluarsa & + & + & - & - \\
\hline
\end{tabular}

$\mathrm{A}, \mathrm{B}, \mathrm{C}$ dan $\mathrm{D}=$ kode sampel

\section{Teknosains : Jurnal Sains, Teknologi dan Informatika is licensed under a Creative} Commons Attribution-NonCommercial 4.0 International License. 


\subsection{Hasil Organoleptik Sampel}

Pemeriksaan organoleptik dilakukan secara pengamatan visual untuk mengetahui karakteristik pada sampel yang meliputi bentuk, warna, dan bau. Organoleptik dilakukan sebelum preparasi sampel, dengan tujuan agar diketahui karakteristik awal sampel krim pemutih wajah yang akan digunakan. Hasil pemeriksaan organoleptik yang diperoleh dapat dilihat pada Tabel 2.

Tabel 2. Data organoleptik sampel "A", "B", "C", dan "D"

\begin{tabular}{lllll}
\hline Keterangan & Sampel A & Sampel B & Sampel C & Sampel D \\
\hline Bentuk & $\begin{array}{l}\text { Setengah } \\
\text { padat }\end{array}$ & Setengah padat & Setengah padat & Setengah padat \\
& Khas & Khas & Khas & Khas \\
Warna & Putih & Coklat muda & Kuning & Kuning \\
\hline
\end{tabular}

Berdasarkan hasil pengamatan warna, dapat diketahui bahwa bahan uji A memiliki warna putih sedangkan bahan uji lainnya menggunakan penambahan zat warna supaya lebih menarik. Semua sampel memenuhi persyaratan dengan hasil bentuk setengah padat dan beraroma khas.

\subsection{Hasil Pembuatan Kurva Kalibrasi dan Linearitas}

Uji linearitas dilakukan dengan membuat lima konsentrasi yang berbeda yaitu $0.313 \mathrm{bpj}$; 0.625 bpj; 1.25 bpj; 2.5 bpj dan 5 bpj yang masing-masing konsentrasinya disuntikan sebanyak $20 \mu \mathrm{l}$ ke dalam alat KCKT. Kemudian kurva kalibrasi dibuat antara konsentrasi terhadap luas area larutan baku pembanding dan ditentukan dengan persamaan garis liniernya.

Parameter hubungan kelinieran yang digunakan yaitu koefisien korelasi ( $r$ ) pada analisis regresi linier $\mathrm{y}=\mathrm{bx}+\mathrm{a}$ ( $\mathrm{b}$ adalah slope, a adalah intersep, $\mathrm{x}$ adalah konsentrasi analit dan $\mathrm{y}$ adalah respon instrumen). Hubungan linier yang ideal dicapai jika nilai $a=0$ dan $r=+1$ atau -1 (Badan POM RI, 2011; Riyanto, 2015).

Berdasarkan perhitungan diperoleh persamaan kurva kalibrasi adalah $\mathrm{y}=467,3396 \mathrm{x}+$ 18.0716. Diperoleh hubungan yang linier antara luas puncak dan konsentrasi dengan koefisien korelasi (r) sebesar 0.9923. Hasil pengujian yang diperoleh memenuhi persyaratan berdasarkan ketentuan umum, yakni harga koefisien korelasi yang baik adalah mendekati 1.000 atau sama dengan 1.000 (Harmita, 2004).

Hasil uji linearitas yang dinyatakan dalam persamaan garis linier dan nilai $r$ dari kurva kalibrasi dapat dilihat pada Tabel 3 dan Gambar 1.

Tabel 3. Data hubungan konsentrasi dengan luas area

\begin{tabular}{cc}
\hline Konsentrasi (bpj) & Luas Area $\left(\mathbf{c m}^{\mathbf{2}}\right)$ \\
\hline $\mathbf{0 , 3 1 3}$ & 469,71368 \\
$\mathbf{0 , 6 2 5}$ & 477,17242 \\
\hline
\end{tabular}

Teknosains : Jurnal Sains, Teknologi dan Informatika is licensed under a Creative Commons Attribution-NonCommercial 4.0 International License.

Analisis Hidrokortison Asetat Dalam Sediaan Krim Pemutih Wajah Secara Kromatografi Cair Kinerja Tinggi (Vol.7, No1) Januari 2020 


\begin{tabular}{cc}
\hline $\mathbf{1 , 2 5}$ & 491,04224 \\
$\mathbf{2 , 5}$ & 519,64142 \\
$\mathbf{5}$ & 554,20636 \\
\hline
\end{tabular}

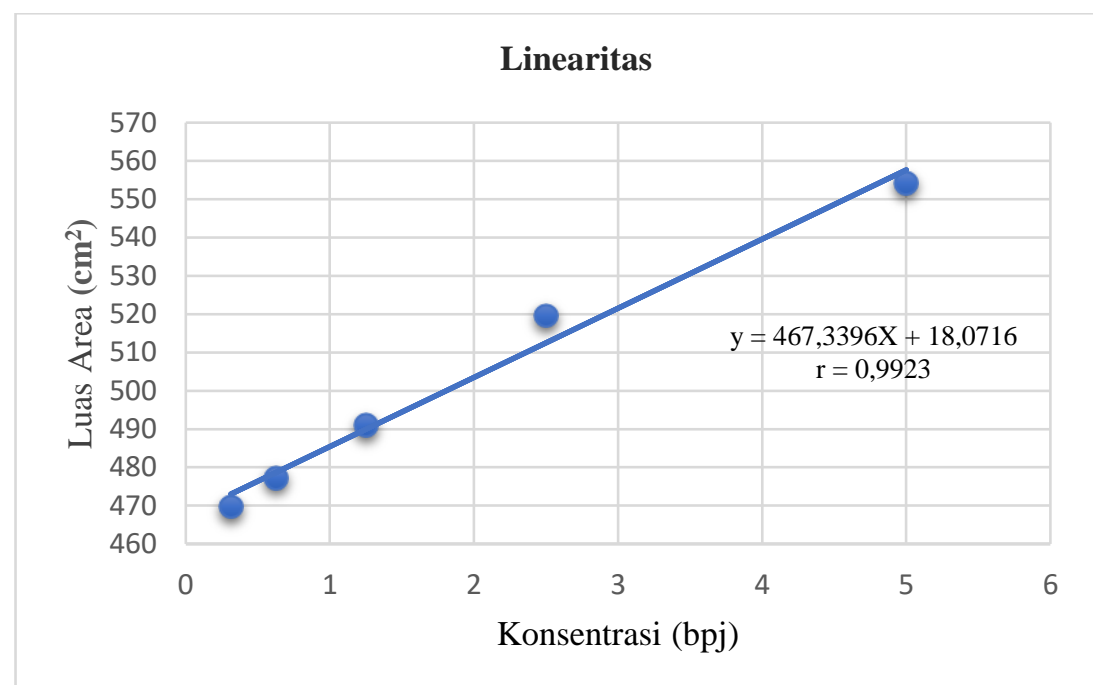

Gambar 1. Kurva kalibrasi standar Hidrokortison Asetat hubungan linier antara Luas area $\left(\mathrm{cm}^{2}\right)$ terhadap konsentrasi (bpj).

Berdasarkan perhitungan diperoleh persamaan kurva kalibrasi adalah $\mathrm{y}=467,3396 \mathrm{x}+$ 18.0716. Diperoleh hubungan yang linier antara luas area $\left(\mathrm{cm}^{2}\right)$ dan konsentrasi (bpj) dengan koefisien korelasi (r) sebesar 0.9923. Hasil pengujian memenuhi persyaratan berdasarkan ketentuan umum yaitu harga koefisien korelasi yang baik adalah mendekati 1 atau sama dengan 1 yang dijelaskan pada tabel 4 (Harmita, 2004).

\subsection{Hasil Penentuan Batas Deteksi (LOD) dan Batas Kuantitatif (LOQ)}

Penentuan batas deteksi dan kuantitasi dihitung secara statistik melalui garis regresi linear yang diperoleh dari kurva kalibrasi. Nilai pengukuran akan sama dengan nilai b pada persamaan garis linier $\mathrm{y}=\mathrm{a}+\mathrm{bx}$, sedangkan simpangan baku blanko sama dengan simpangan baku residual (Sy/x) (Harmita, 2004; Riyanto, 2015).

Berdasarkan hasil pengukuran didapatkan nilai batas deteksi (LOD) sebesar $72601 \mu \mathrm{g} / \mathrm{mL}$ pada panjang gelombang $252 \mathrm{~nm}$ dan batas kuantitasi (LOQ) sebesar $24,2004 \mu \mathrm{g} / \mathrm{mL}$ pada panjang gelombang $252 \mathrm{~nm}$, yang berarti jumlah dan konsentrasi terkecil kadar hidrokortison asetat dalam sampel dapat dideteksi dengan respon yang signifikan pada analisis menggunakan KCKT (Harmita, 2004).

\subsection{Hasil Uji Presisi}

Uji presisi ini diukur sebagai simpangan baku atau simpangan baku relatif (koefisien variasi). Precision dapat dinyatakan sebagai repeatability (keterulangan) atau reproducibility (ketertiruan) (Harmita, 2004; Riyanto, 2015). Analisis terhadap parameter keseksamaan ini

Teknosains : Jurnal Sains, Teknologi dan Informatika is licensed under a Creative Commons Attribution-NonCommercial 4.0 International License.

Analisis Hidrokortison Asetat Dalam Sediaan Krim Pemutih Wajah Secara Kromatografi Cair Kinerja Tinggi (Vol.7, No1) Januari 2020 
dilakukan dengan menginjeksi ke alat KCKT larutan hidrokortison asetat 2.5 bpj dengan 5 kali replikasi. Hasil pengukuran uji presisi dapat dilihat pada Tabel 4.

Tabel 4. Hasil uji rata-rata presisi

\begin{tabular}{cc}
\hline \multicolumn{1}{c}{ Keterangan } & Luas Area $\left(\mathbf{c m}^{\mathbf{2}}\right)$ \\
\hline Replikasi 1 & 516,38 \\
Replikasi 2 & 518,09 \\
Replikasi 3 & 517,18 \\
Replikasi 4 & 519,09 \\
Replikasi 5 & 516,27 \\
Rata-rata & 517,402 \\
SD & 1,194 \\
RSD & $0,23 \%$ \\
\hline
\end{tabular}

Berdasarkan data pada Tabel 4, diperoleh nilai RSD sebesar $0.23 \%$ menunjukkan bahwa metode analisis yang digunakan memenuhi kriteria untuk suatu metode analisis yang seksama dan teliti. Kriteria ketelitian diberikan jika metode memberikan simpangan baku relatif $\leq 2 \%$. Makin kecil simpangan baku relatif yang diberikan suatu metode analisis maka kesahihan metode tersebut lebih terjamin (Harmita, 2004).

\subsection{Hasil Uji Perolehan Kembali (Recovery).}

Uji akurasi dilakukan dengan menggunakan metode penambahan baku (the method of standard additives), yakni ke dalam sampel krim pemutih wajah dengan kode sampel A ditambahkan hidrokortison asetat baku sebanyak $100 \%$ dari rerata kadar hidrokortison asetat yang terdapat pada sampel, kemudian dianalisis dengan prosedur yang sama seperti pada sampel. Hasil dinyatakan dalam persen perolehan kembali (\% recovery) (Harmita, 2004; Riyanto, 2015).

Uji akurasi perolehan kembali ini dilakukan penetapan dengan penambahan dua konsentrasi standar yang berbeda yaitu standar dengan konsentrasi 0,313 dan $1.25 \mathrm{bpj}$. Masingmasing standar diambil sebanyak $1.0 \mathrm{~mL}$, kemudian dicampur dengan $1.0 \mathrm{~mL}$ larutan sampel yang diperiksa. Hasil percobaan dapat dilihat pada Tabel 5.

Tabel 5. Hasil uji akurasi perolehan kembali.

\begin{tabular}{ccccc}
\hline Replikasi & $\begin{array}{c}\text { Luas Area } \\
\text { Larutan } \\
\text { sampel }\left(\mathbf{c m}^{2}\right)\end{array}$ & $\begin{array}{c}\text { Luas area } \\
\text { sampel + standar } \\
\mathbf{0 , 3 1 3} \mathbf{~ b p j}\left(\mathbf{c m}^{2}\right)\end{array}$ & $\begin{array}{c}\text { \% } \\
\text { Recovery }\end{array}$ & $\begin{array}{c}\text { Rata-rata \% } \\
\text { Recovery }\end{array}$ \\
\hline 1 & 42,12537 & 48,053125 & 97,74883 & \\
2 & 42,58399 & 49,002365 & 98,87699 & $98,24 \%$ \\
3 & 42,15271 & 47,502351 & 98,10939 & \\
\hline
\end{tabular}

Teknosains : Jurnal Sains, Teknologi dan Informatika is licensed under a Creative Commons Attribution-NonCommercial 4.0 International License. 


\begin{tabular}{ccccc} 
Replikasi & $\begin{array}{c}\text { Luas Area } \\
\text { Larutan } \\
\text { sampel }\left(\mathbf{c m}^{2}\right)\end{array}$ & $\begin{array}{c}\text { Luas area } \\
\text { sampel + standar } \\
\mathbf{1 , 2 5} \mathbf{b p j}\left(\mathbf{c m}^{2}\right)\end{array}$ & $\begin{array}{c}\text { \% } \\
\text { Recovery }\end{array}$ & $\begin{array}{c}\text { Rata-rata \% } \\
\text { Recovery }\end{array}$ \\
\hline 1 & 42,12537 & 49,747522 & 98,70687 & \\
2 & 42,12537 & 49,754892 & 99,20076 & $98,84 \%$ \\
3 & 42,15271 & 49,678253 & 98,60611 & \\
\hline
\end{tabular}

Berdasarkan data pada Tabel 5, diperoleh nilai akurasi \% recovery sebesar 98,24\% dan $98,84 \%$, yang berarti bahwa metode yang digunakan cukup akurat untuk menganalisis, sebab nilai rentang rata-rata \% recovery yang dihasilkan berada pada rentang yang diijinkan, yaitu 80 $120 \%$ (Harmita, 2004).

\subsection{Hasil Uji Kualitatif Waktu Retensi dan Kuantitatif Luas Area Kromatogram Sampel}

Penelitian ini menggunakan data luas area yang diperoleh untuk menghitung kadar, sebab luas area kromatogram sangat proposional dengan konsentrasi analit. Setelah dipastikan terdapat luas area pada sampel yang diuji berdasarkan waktu retensi dari standar analit, maka dilakukan penentuan kadar. Kurva baku yang telah dibuat dapat digunakan dalam mengukur kadar dari Hidrokortison Asetat dengan membuat hubungan antara luas area kromatogram dengan konsentrasi.

Pada hasil pengujian dengan metode KCKT didapat waktu retensi yang diperoleh untuk senyawa Hidrokortison Asetat adalah 1,668 menit. Pada percobaan sampel krim pemutih wajah merek A, B, C dan D terdapat puncak atau nilai luas area pada waktu retensi 1,668 menit. Hasil analisis data secara kualitatif dapat dilihat pada Tabel 6.

Tabel 6. Data hasil analisis kualitatif waktu retensi baku hidrokortison asetat dan sampel

\begin{tabular}{cccc}
\hline Kode & Waktu retensi & $\begin{array}{c}\text { Waktu } \\
\text { retensi }\end{array}$ & RSD \\
Sampel & $\begin{array}{c}\text { rata-rata baku } \\
\text { hidrokortison } \\
\text { asetat (menit) }\end{array}$ & Sampel & $\mathbf{( \% )}$ \\
& & (menit) & \\
\hline & & 1,657 & \\
A & & 1,656 & 0,06 \\
& & 1,658 & \\
B & & 1,658 & \\
& 1,668 & 1,657 & 0,09 \\
& & 1,655 & \\
& & 1,649 &
\end{tabular}

Teknosains : Jurnal Sains, Teknologi dan Informatika is licensed under a Creative

Commons Attribution-NonCommercial 4.0 International License.

Analisis Hidrokortison Asetat Dalam Sediaan Krim Pemutih Wajah Secara Kromatografi Cair Kinerja

Tinggi (Vol.7, No1) Januari 2020 


$\begin{array}{lll}\mathrm{C} & 1,652 & 0,18 \\ & 1,655 & \\ & 1,659 & \\ \mathrm{D} & 1,658 & 0,06 \\ & 1,657 & \end{array}$

Sampel dinyatakan mengandung hidrokortison asetat jika puncak pada kromatogram sampel dan puncak pada kromatogram bahan pembanding memiliki waktu retensi yang tidak jauh berbeda yaitu $\pm 5 \%$ dari waktu retensi puncak hidrokortison asetat (Badan POM RI, 2011). Hasil kromatogram dapat dilihat pada Gambar 2, 3, 4 dan 5.

Data luas area yang diperoleh untuk menghitung kadar, sebab luas area kromatogram sangat proposional dengan konsentrasi analit. Setelah dipastikan terdapat luas area pada sampel yang diuji berdasarkan waktu retensi dari standar analit, maka dilakukan penentuan kadar. Kurva baku yang telah dibuat dapat digunakan dalam mengukur kadar dari hidrokortison asetat dengan membuat hubungan antara luas area kromatogram dengan konsentrasi.

Dilakukan perhitungan menggunakan persamaan garis $\mathrm{y}=467,3396 \mathrm{x}+18.0716(\mathrm{y}=$ luas area yang didapat dan $\mathrm{x}=$ konsentrasi analit) untuk menentukan kadar sampel krim pemutih wajah merek A, B, C dan D berdasarkan nilai luas area yang diperoleh. Hasil perhitungan kadar sampel krim pemutih wajah merek A, B, C dan D dapat dilihat pada Tabel 7.

Tabel 7. Hasil uji kuantitatif senyawa hidrokortison asetat

\begin{tabular}{ccccc}
\hline Kode & Replikasi & Luas area & Kadar & $\begin{array}{c}\text { Rata- } \\
\text { rata } \\
\text { kadar } \\
\text { Sampel }\end{array}$ \\
\hline \multirow{2}{*}{ A } & 1 & 42,12537 & 1,0465 & \\
\hline & 2 & 42,58399 & 1,0658 & 1,0583 \\
& 3 & 42,49782 & 1,0627 & \\
& 1 & 24,08646 & 0,2641 & \\
B & 2 & 26,27606 & 0,3583 & 0,3316 \\
& 3 & 26,58736 & 0,3726 & \\
& 1 & 22,27606 & 0,1869 & \\
C & 2 & 21,17060 & 0,1378 & 0,1513 \\
& 3 & 20,98065 & 0,1293 & \\
& 1 & 44,46941 & 1,1619 & \\
& 2 & 41,55397 & 1,0336 & 1,1662 \\
& 3 & 47,67854 & 1,3032 & \\
\hline
\end{tabular}

Teknosains : Jurnal Sains, Teknologi dan Informatika is licensed under a Creative Commons Attribution-NonCommercial 4.0 International License.

Analisis Hidrokortison Asetat Dalam Sediaan Krim Pemutih Wajah Secara Kromatografi Cair Kinerja Tinggi (Vol.7, No1) Januari 2020 
Berdasarkan data pada Tabel 7, didapatkan kadar rata-rata sampel krim pemutih wajah merk A sebesar $1,0583 \mu \mathrm{g} / \mathrm{g}$; merek Bsebesar 0,3316 $\mu \mathrm{g} / \mathrm{g}$; merek C sebesar 0,1513 $\mu \mathrm{g} / \mathrm{g}$; dan merek D sebesar 1,1662 $\mu \mathrm{g} / \mathrm{g}$. Hasil pengujian kuantitatif secara KCKT ini membuktikan bahwa krim pemutih wajah yang teregistrasi, registrasi palsu dan tidak teregistrasi mengandung Hidrokortison Asetat.

Berdasarkan Peraturan Kepala BPOM RI Nomor 18 tahun 2015 tentang Persyaratan Teknis Bahan Kosmetik, Hidrokortison Asetat tidak diperkenankan terdapat pada sediaan untuk perawatan kulit, sehingga kadar sekecil apapun dilarang terdapat pada sediaankrim pemutih wajah. Dari hasil penelitian menunjukkan adanya kandungan hidrokortison asetat pada sampel. Oleh karena itu, perlu pengawasan BPOM yang lebih ketat terhadap sediaan krim pemutih wajah yang teregistrasi dan tidak teregistrasi (BADAN POM RI, 2015).

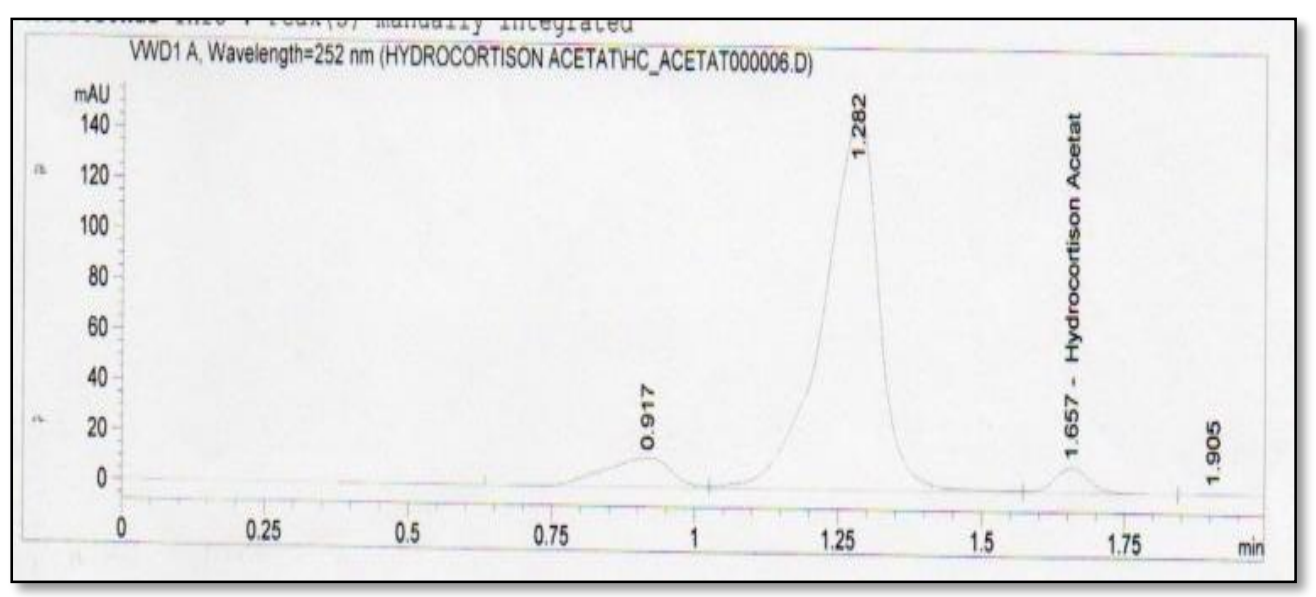

Gambar 2. Hasil kromatogram KCKT sampel krim pemutih yang positif mengandung senyawa hidrokortison asetat (sampel aeregistrasi)

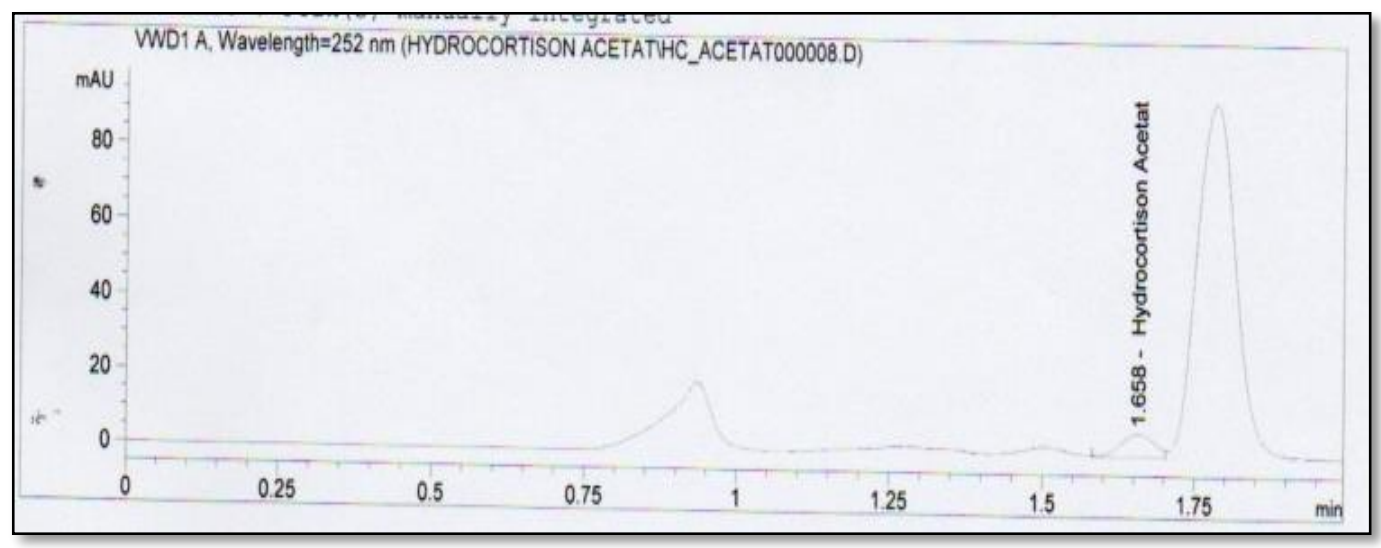

Gambar 3. Hasil kromatogram KCKT sampel krim pemutih yang positif mengandung senyawa hidrokortison asetat (sampel B teregistrasi)

Teknosains : Jurnal Sains, Teknologi dan Informatika is licensed under a Creative Commons Attribution-NonCommercial 4.0 International License.

Analisis Hidrokortison Asetat Dalam Sediaan Krim Pemutih Wajah Secara Kromatografi Cair Kinerja Tinggi (Vol.7, No1) Januari 2020 


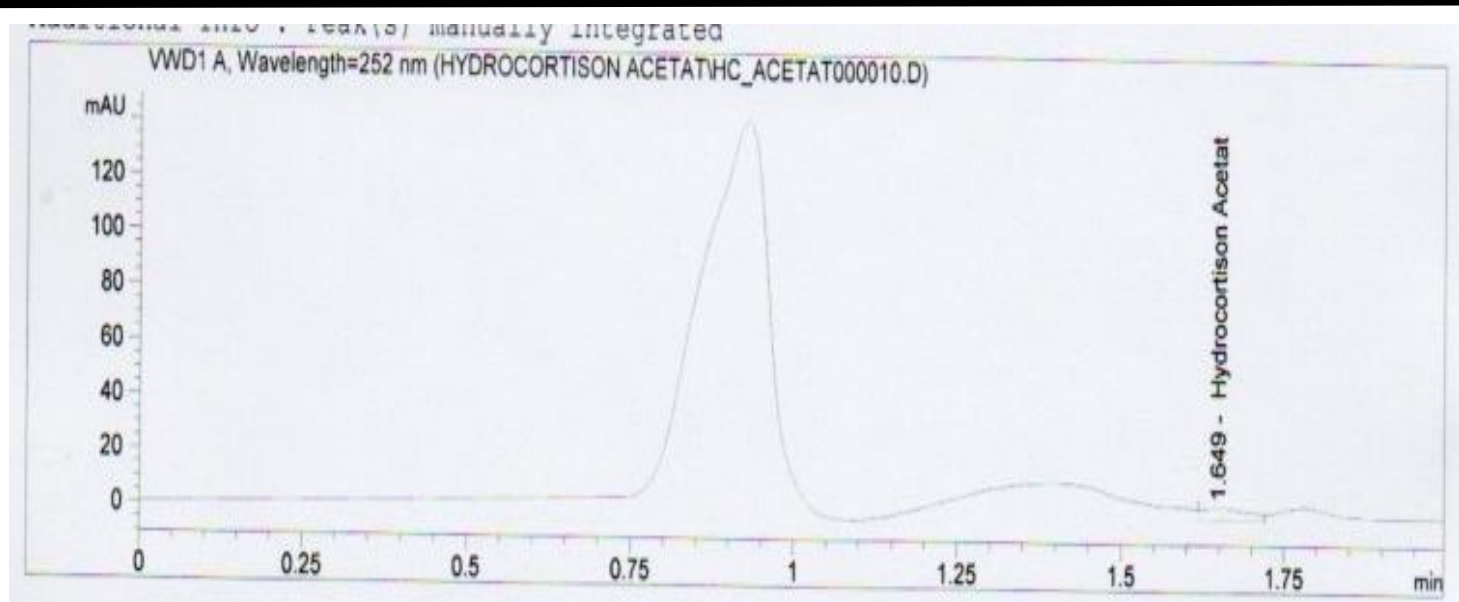

Gambar 4. Hasil kromatogram kckt KCKT sampel krim pemutih yang positif mengandung senyawa hidrokortison asetat (sampel C teregistrasi palsu)

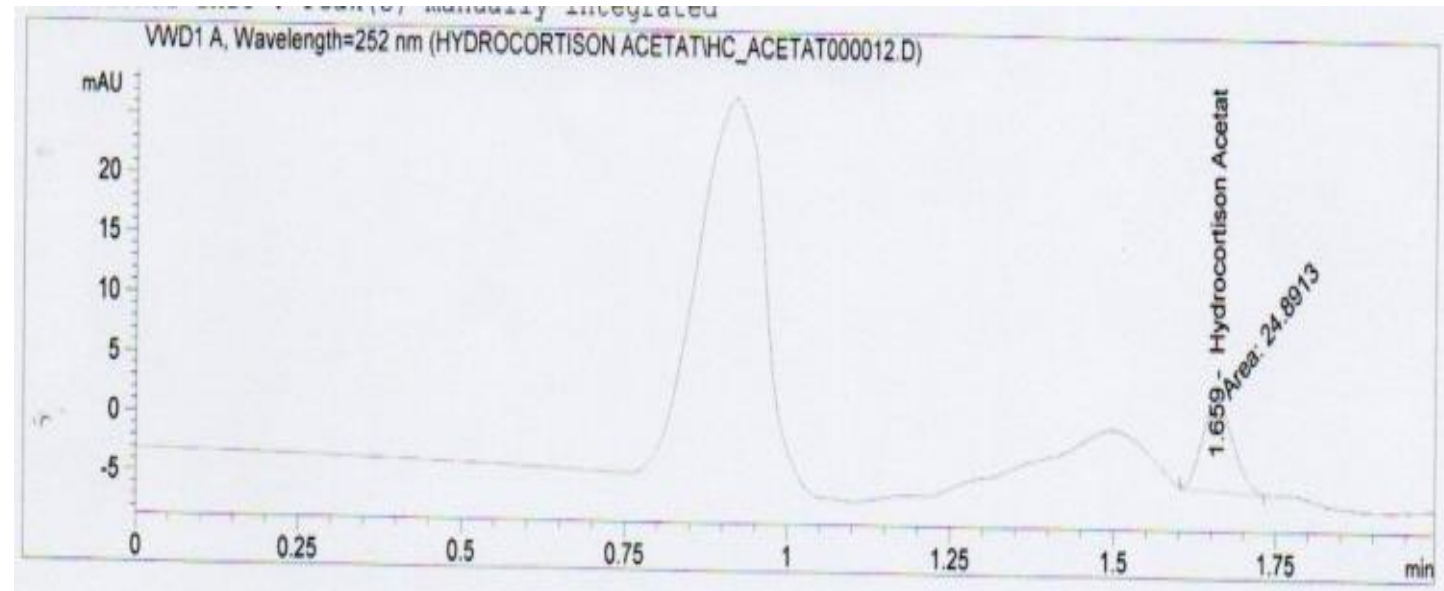

Gambar 5. Hasil kromatogram KCKT sampel krim pemutih yang positif mengandung senyawa hidrokortison asetat (sampel D tidak teregistrasi)

\section{SIMPULAN}

Hasil analisis menunjukkan kondisi pemisahan yang baik menggunakan metode KCKT dengan kolom $\mathrm{C}_{18}$, fase gerak asetonitril: aquabides $(60: 40 \mathrm{v} / \mathrm{v})$, laju alir $1.0 \mathrm{ml} / \mathrm{menit}$, detektor $\mathrm{UV} \lambda$ $252 \mathrm{~nm}$. Semua komponen terpisah baik dalam waktu analisis kurang dari 2.0 menit. Hasil validasi metode menunjukan bahwa metode yang digunakan dalam penelitian ini memenuhi persyaratan akurasi, presisi, linieritas, LOD dan LOQ. Hasil penelitian menunjukkan metode memiliki linieritas yang baik $(r=0.9923)$. Hasil akurasisebesar $98.24 \%$ dan $98.84 \%$. Hasil presisi sebesar $0.23 \%$. Hasil LOD sebesar $7.2601 \mu \mathrm{g} / \mathrm{mL}$ dan hasil LOQ sebesar 24.2004 $\mu \mathrm{g} / \mathrm{mL}$.Berdasarkan hasil yang diperoleh keempat sampel krim mengandung hidrokortison

Teknosains : Jurnal Sains, Teknologi dan Informatika is licensed under a Creative Commons Attribution-NonCommercial 4.0 International License.

Analisis Hidrokortison Asetat Dalam Sediaan Krim Pemutih Wajah Secara Kromatografi Cair Kinerja Tinggi (Vol.7, No1) Januari 2020 
asetat dengan kadar masing-masing sampel $\mathrm{A}=1.0583 \mu \mathrm{g} / \mathrm{g}$, sampel $\mathrm{B}=0.3316 \mu \mathrm{g} / \mathrm{g}$, sampel C $=0.1513 \mu \mathrm{g} / \mathrm{g}$, dan sampel $\mathrm{D}=1.1662 \mu \mathrm{g} / \mathrm{g}$.

\section{DAFTAR PUSTAKA}

Badan POM RI. Peraturan Kepala Badan Pengawas Obat Dan Makanan Republik Indonesia Tahun 2011 Tentang Metode Analisis Kosmetika, Pub. L. No. HK.03.1.23.08.11.07331 Tahun 2011, 1 (2011). Indonesia.

Badan POM RI. Perubahan Atas Peraturan Kepala Badan Pengawas Obat dan Makanan Nomor 1 Tahun 2016 Tentang Pedoman Teknis Pengawasan Iklan Kosmetika, Pub. L. No. 18 Tahun 2016, 1 (2016). Indonesia.

BADAN POM RI. Rencana Strategis Biro Umum Badan Pengawas Obat dan Makanan Tahun 2015 tentang Persyaratan Teknis Bahan Kosmetik, Pub. L. No. HK.04.2.24.06.15.04189 Tahun 2015, 1 (2015). Indonesia.

Goldman, M. P., \& Weiss, R. A. (2011). Sclerotherapy Treatment of Varicose and Telangiectatic Leg Veins (6th Ed). London: Elsevier.

Harmita. (2004). Petunjuk Pelaksanaan Validasi Metode dan Cara Penggunaannya. Majalah Ilmu Kefarmasian, I(3), 117-135.

Menteri Kesehatan Republik Indonesia. Peraturan Menteri Kesehatan Republik Indonesia Tentang Izin Produksi Kosmetika, Pub. L. No. 1175/MENKES/PER/VIII/2010, 1 (2010). Indonesia.

Menteri Kesehatan Republik Indonesia. Peraturan Menteri Kesehatan Republik Indonesia Tentang Notifikasi Kosmetika, Pub. L. No. 1176/MENKES/PER/VIII/2010, 1 (2010). Indonesia.

Mohd Zukepli, N. W., Zakaria, S. R., \& Wan Omar, W. S. A. (2015). Assessment on hyroquinone in selected cosmetic cream and toner via high performance liquid chromatography and ultra-violet visible detector spectrometry. Malaysian Journal of Analytical Sciences, 19(4), 824-830.

Ritter, J. M., Lewis, L. D., Mant, T. G., \& Ferro, A. (1981). Clinical Pharmacology and Therapeutics (5th ed.). Great britain: Hodder Arnold.

Riyanto. (2015). Validasi \& Verifikasi Metode Uji Sesuai dengan ISO/IEC 17025 Laboratorium Pengujian dan Kalibrasi (1st Ed). Sleman, Yogyakarta: deepublish.

Teknosains : Jurnal Sains, Teknologi dan Informatika is licensed under a Creative Commons Attribution-NonCommercial 4.0 International License. 